Behavioural Sciences | Dr Anthony Nyberg

\section{In search of the perfect leader}

Selecting the next CEO

On most days of the week, the business news will carry a story of at least one Fortune 500 CEO eaving their role; some for the next big role in a gilded career, thers less willingly leaving and thinking and he perks, he most of a less than stellar track record. For the company. and in particular the board of directors, the immediate challenge is succession. What skill set is needed and who might be out there? For Dr Anthony Nyberg, of the Center

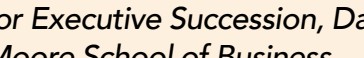
University of South Caroling, and his colleagues, examining the process by which boards recruit a new CEO has identified some fascinating insights.

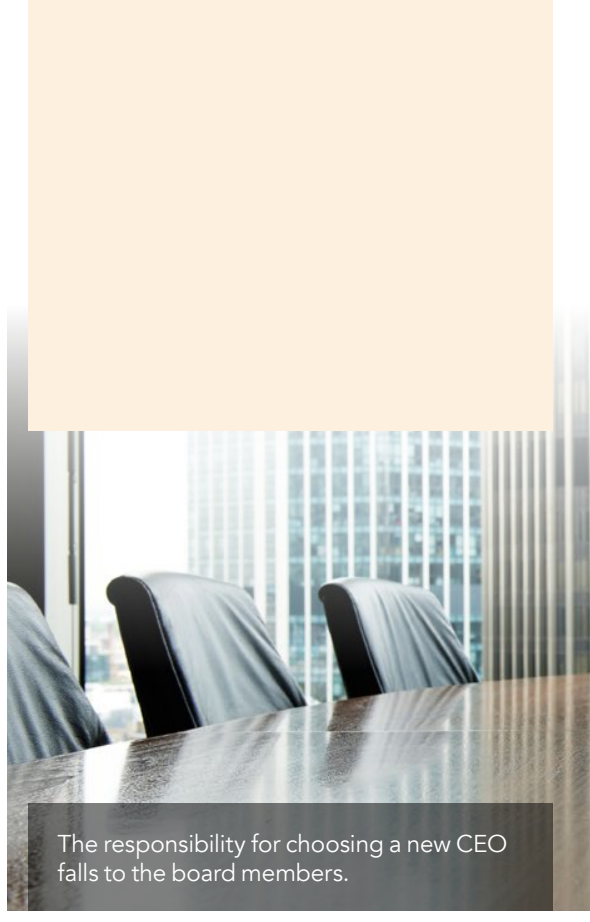

nowing how to choose new people for a company is a challenge that is never finished. Strategies
finding and choosing talent are as diverse as the pool of people available and approaches to the task range from of personal 'yut reastinct, to a battery numerical), and structured evaluations.

When that 'job' is the role of CEO in say, a major Fortune 500 company, the stakes are immense. A square peg in a round hole can quickly break a company an inspired leader, on the other hand, can breathe new life into a drifting business hulk.

So, how does the board of one of these top companies go about the process? The question is intriguing because, surprisingly, selecting a new CEO is often the most important and direct involvement that the board has with

In day-to-day business, the CEO runs the company and reports to the members of the board. For those board members it is often true that their knowledge of the intimate details of the business, that is above and beyond what the interested public might know, is subject to is subject to what
But board members have a fiduciary duty to the shareholders, a duty to act in the best interests of the company, and that means finding the $\mathrm{CEO}$ who is the very best fit. The incumbent CEO has the same fiduciary duty but their legal duty, they leave the job.

\section{THE CHALLENGE}

The 'gut instinct' approach to selecting CEO is less prevalent (although perhap - especially in smaller companies), driven by the great strides in equal opportunity legislation, the highly expensive risk of prejudice law-suits and the enlightened, if belated, recognition of the value of diversity. responsibility has been greatly expande by the growing focus on corporate governance and the legislation that public corporate scandals.

But procedures are not only driven by the threat of 'getting it wrong', they practice in a highly competitive world.

Take the case of McDonalds in 2004. Tragically, their highly successful CEO,
For the top companies, that burden of

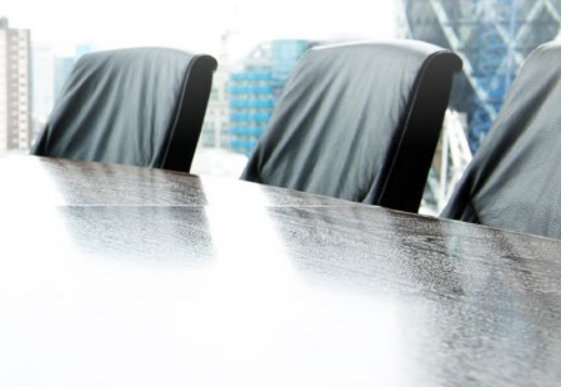

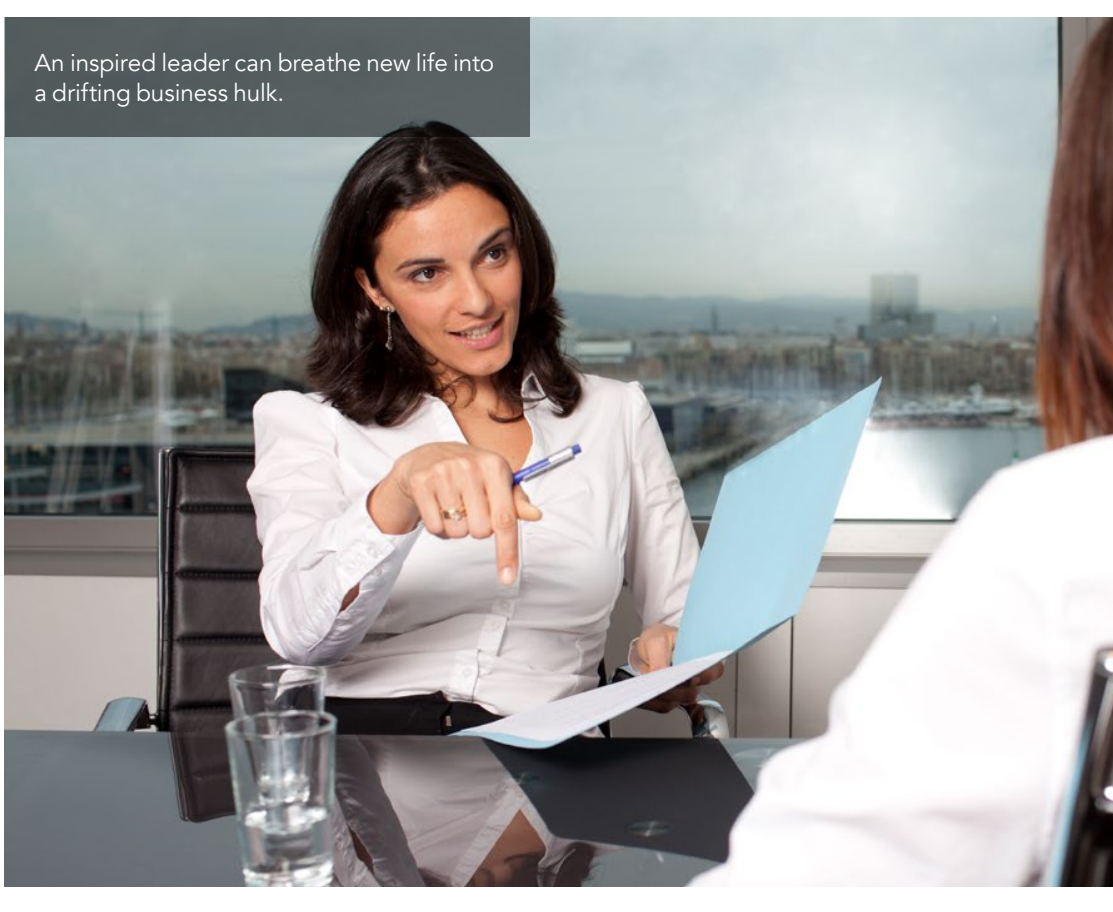

Jim Cantalupo, suffered a fatal heart attack overnight on 19 April 2004, at just 60 year ach is successor in the role (Gibson and Gray, 2004). The Economist magazine (2004) mmediately described the speed of reaction as "a board acting at its finest" .

The focus of Dr Anthony Nyberg and his colleagues is not how company boards respond to tragic events or unforeseen legal scandal, but how, in all situations, they prepare for and go about the absolutely foreseeablo need to eventually find a new CEO

The title of their paper captures the key issues well: "Planning for future formalized succession processes, and CEO influence in CEO succession planning". This problem is increasing in importance as CEO tenure rates in large-cap (S\&P 500) companies are falling: a median of 5 years in 2017 compared to 7.5 years in 2013 (Marcec D, 2018).

That means that for many companies this is a frequent challenge, or, as on of the study's respondents stated. We begin planning for the next CEO succession the first day our CEO takes offce." To this end, we are concerned of moce wis the srategic responsiblity of succession planning than the ever-changing technical challenge, the
PROCEDURAL RATIONALITY Behaviour is considered procedurally deliberation, a deliberate set of processes designed to reach an informed decision. It is closely aligned to the psychological construct of bounded rationality and, indeed, rationality as acc

Finding that special person with the particular skill-sets demanded by the charismatic leadership qualties that can

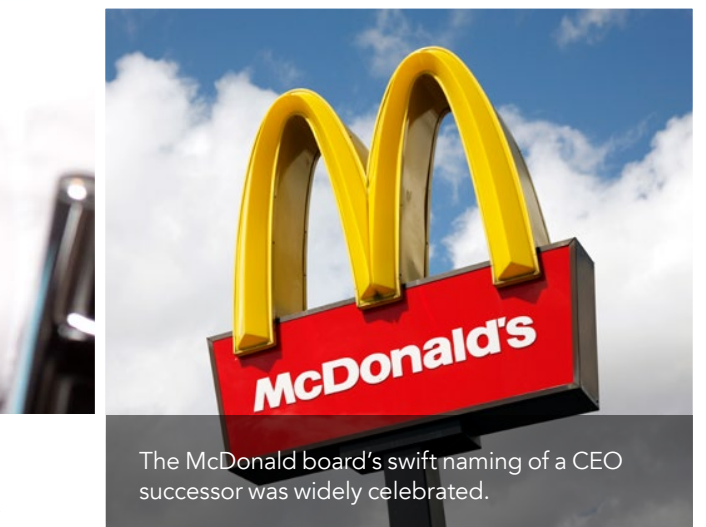

formalised CEO succession planning would increase the likelihood of successor candidate, of having an interna candidate and of drawing on external help and would reduce the anticipated time needed to name a permanent CEO.

These elements have multiple benefits; considering multiple candidates helps exact replica of the existing CEO;

We begin planning for the next CEO succession the first day our CEO takes office.

innovative and disruptive market leader and a track record that will persuade the the premium necessary takes time - often a lot of time.

Much of that time will be spent reaching a consensus on 'what' is required, befor the board can even start the process of putting some possible names to the question of 'who'. In the current context, CEO recruitment, there is considerable evidence that an approach based on procedural rationality will lead to a superior outcome compared to less

So, in this element of the study, the research team hypothesised that internal candidates may well come with wealth of industry market experience, understanding of the culture, and very often, a lot of relevant and potentially expert involvement can plug gaps in the existing CEO and board's knowledge and experience to effectively 'design' the role of the next CEO

And timing? In the example of McDonalds, described above, if the board had started the process only on hearing of Jim Cantalupo's death, a lot his successful wrould have been lost from his successful strategic intiatives. The fact that scenario and contingency planning 


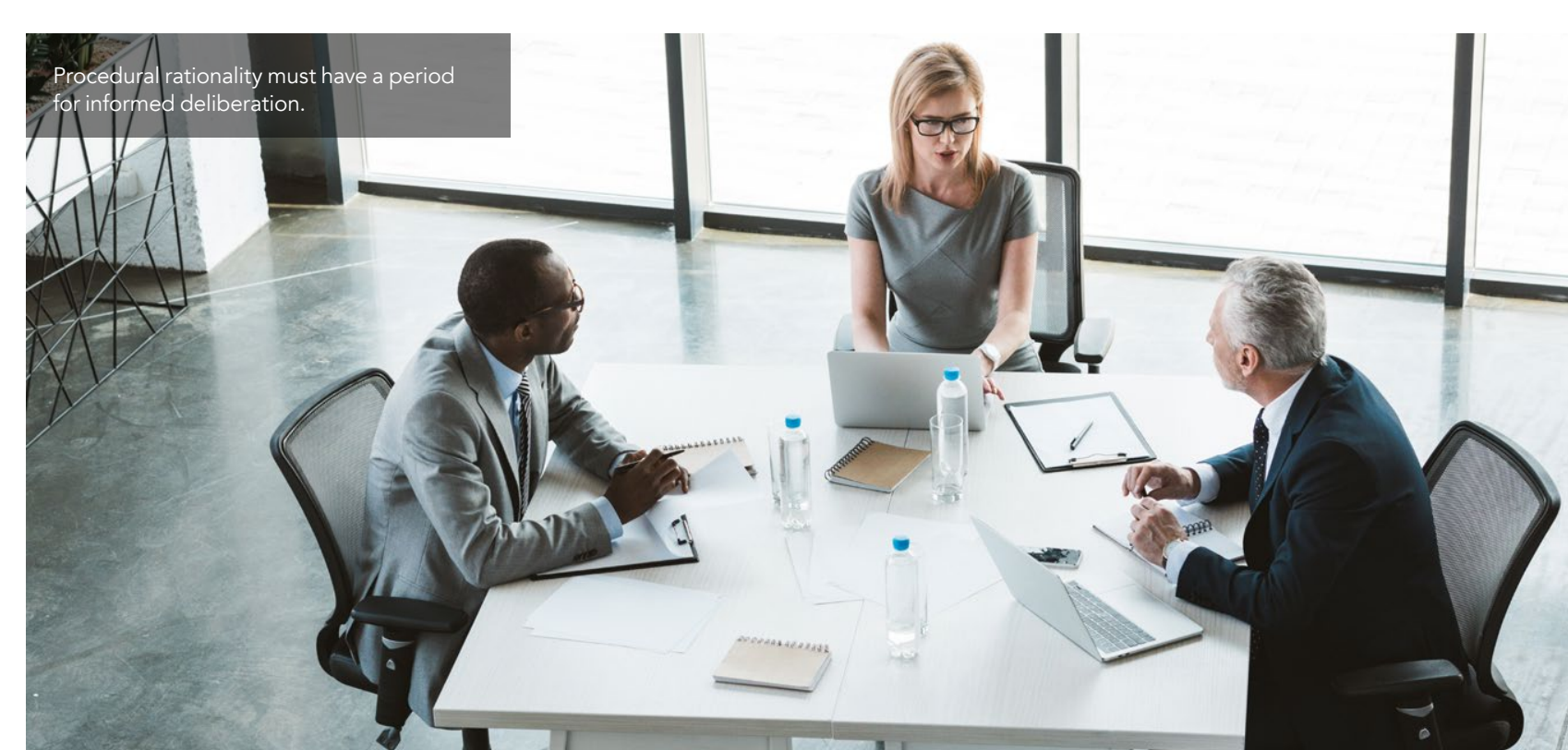

approach meant that the momentum have a period for informed deliberation if the outcome is to be positive and planning ahead is key.

\section{THE INCUMBENT CEO}

The CEO may well act as gatekeeper for the level, quality and objectivity of to the board. That can be a highly significant issue in trying to ensure an effective, procedurally rational process.

There are many reasons why a new CEO may be appointed. In many cases, the incumbent $\mathrm{CEO}$ outgrows their existing employer. As an even higher flyer, their advice and involvement could be critica to the bord in for thing the template causal scale is the CEO who has failed to deliver results or even worse, those whose self-interest, or belief in their ow infallibility, has not only ruined their ow careers (and possibly freedom) but may also have done terminal damage to the brands they fronted. Without the Enron Corporation and Arthur Anderson, there may be no Sarbanes-Oxley

So how involved should the existing CEO be in the process of selecting their successor?
Here the research team hypothesised that CEO influnce in succession planning of considering more than on CEO successor candidate, of having an inter candidate and of drawing on external. help, and would increase the time needed to name a permanent CEO.

They reasoned that CEOs often already have a good idea of who their replacement should be, that as natura leaders they do not always like taking advice and that involvement and influence of the existing CEO can make a big difference to how long the whole process takes. A value of procedural rationality is that it helps to lead to more systematic essence, hus decision will be reached than if such an approach is not in place.

The final hypothesis comes, perhaps, from the findings of the other eight: $C E O$ influence moderates the relationship between formalised succession process and succession planning outcomes (multiple successor candidates, likelihood successor, use of external help) such that, when CEO influence is high,

No matter how strong your internal person is, you must do an external search to ensure you have the best. decisions; thus, even if speed is of the of internal successor, time to permanent the relationship between formalise succession planning processes and

TESTING THE HYPOTHESES To test these theoretically generated in-depth qualitative interviews. To this, they added unique survey and archival dita from 355 firm-year observations of 218 large organisations, collected over three multiple techniques to ensure the study's findings were robust.

\section{CONCLUSION}

The study's findings supported the first set of hypotheses, that formalised CEO seclihood CEO sud of considening more than one CEO succossor candida, havng an help, and would reduce the anticipated time needed to name a permanent CEO

However, they were not able to find support for their theory that CEO involvement in the succession planning process influenced the outcome. The researchers concluded that boards appear to approach CEO succession planning processes more independently of $\mathrm{CEO}$ influence than may have been assumed and illustrated in prior research.

The researchers' work supports the need for procedural rationality well in advance to start or the recruitment process CEO succession. years. The results were analysed using

\section{Behind the Research}

Dr Anthony Nyberg

E: Anthony.Nyberg@moore.sc.edu T: +1 8037775974 W: https://sc.edu/study/colleges_schools/ moore/research_and centers/centers/center for executive_succession/index.php

\section{Research Objectives}

Dr Nyberg and his colleagues have examined the processes

\section{Detail}

1014 Greene Street

Columbia

Bio

Anthony J. Nyberg is a Professor and Distinguished Moore Research Fellow in the Darla Moore School of Business. His primary research examines how firms compete through people, specifically the strategic role of pay in the attraction, emergence, retention, and motivation of human capital resources, including the top management team.

Funding

Center for Executive Successio

\section{collaborators}

Corlaboration between DJ Schepker, Anthony Nyberg, Patrick Wright, and Mike Ulrich.

Uof Center for

Executive Succession Darla Moore School of Business

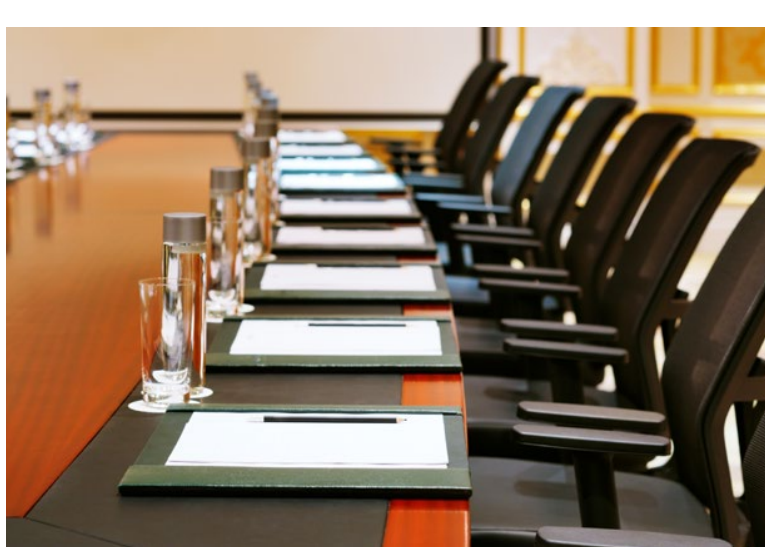

\section{References}

Marcec D, CEO Tenure Rates: Corpgov.law.harvard.edu. (2019). CEO Tenure Rates. [online) Available at: https:/l corpgov.law.harvard.edu/2018/02/12/ceo-tenure-rates/ Accessed 8 Oct. 2019]

Procedural Rationality - an overview I ScienceDirect Topics. Ionline] Available at: https://www.sciencedirect.com/topics/ .

Nyberg, A.J., Schepker, D.J., Wright, P., \& Cragun, O. (2016) Succession planning: Talent management's forgotten, but critical tool. Invited to

Ormonde R. Cragun, Anthony J. Nyberg, Patrick M. Wright, (2016),"CEO succession: what we know and where to go?", Journal of Organizational Effectiveness: People and Performance, Vol. 3 Iss 3 pp. 222-264.

Schepker et al, Planning for Future Leadership: Procedura Rationality, Formalized Succession Processes, and CEO influence in Chief Execulive Officer Succession Planning, The Academy of Management Journal 61(2):amj.2016.0071 August 20172.

\section{Personal Response}

Do you think the involvement, or not, of the incumbent CEO, should be formally voted on by the remaining

No. It is impossible to keep a CEO entirely out of the process, nor, in general, would a board want to keep the CEO out. The CEO ought to have great knowledge about internal candidates) and an understanding a $(p)$ the requirements for filling the job. Additionally, CEOs are inherently involved because they are frequently in charge of providing potential candidates with development opportunities. The key is to create a successful partnership who owns the process, and the CEO, who champion it internally. 